\title{
Stage IA Pancreatic Cancer AJCC v6 and v7
}

National Cancer Institute

\section{Source}

National Cancer Institute. Stage IA Pancreatic Cancer A/CC v6 and v7. NCI Thesaurus.

Code C88100.

Stage IA includes: T1, N0, M0. T1: Tumor limited to the pancreas, $2 \mathrm{~cm}$ or less in

greatest dimension. N0: No regional lymph node metastasis. M0: No distant metastasis.

(from AJCC 7th Ed.) 